\title{
The effect of varying the causes of environmental problems on stated WTP values: evidence from a field study is
}

\author{
Erwin Bulte $^{\mathrm{a}}$, Shelby Gerking ${ }^{\mathrm{b}, *}$, John A. List ${ }^{\mathrm{c}}$, Aart de Zeeuw ${ }^{\mathrm{a}}$ \\ ${ }^{a}$ Department of Economics and CentER, Tilburg University, USA \\ ${ }^{\mathrm{b}}$ Department of Economics, University of Central Florida, P. O. Box 161400, Orlando, FL 32816-1400, USA \\ ${ }^{\circ} A R E C$ and Department of Economics, University of Maryland and NBER, USA
}

Available online 27 September 2004

\begin{abstract}
Standard applications of utility theory assume that utility depends solely on outcomes and not on causes. This study uses a field experiment conducted in the Netherlands to determine if alternative causes of an environmental problem affect willingness to pay to ameliorate it. We find evidence supporting the hypothesis that people are willing to pay significantly more to correct problems caused by humans than by nature (the "outrage effect"), but find no support for the hypothesis that "moral responsibility" matters. We also find support for the hypothesis that stated willingness to pay values obtained via "cheap talk" and "consequential" treatments are lower than without inclusion of these protocols.
\end{abstract}

(C) 2004 Elsevier Inc. All rights reserved.

JEL classification: C93; Q28

Keywords: Field experiment; Endangered species; Non-market valuation

\footnotetext{
${ }^{2}$ We thank Anna Alberini, Mark Dickie, Glenn Harrison, Joseph Herriges, J. Walter Milon, Laura Taylor, and three anonymous referees for useful discussion as well as Seth Jacobs for research assistance. The Galloway Endowment at the University of Central Florida and CentER Data provided research funds. Any errors or omissions remain our responsibility.

${ }^{*}$ Corresponding author. Fax: + 1-407-823-3269.

E-mail address: sgerking@bus.ucf.edu (S. Gerking).
} 


\section{Introduction}

Outcomes of environmental valuation studies frequently are interpreted through the lens of a 'purchase model' [13] in which utility is a function of outcomes or consequences only. This perspective has been challenged both by psychologists and economists who have recognized the importance of attributes of the choice being made. For example, Kahneman et al. [13], Kahneman and Ritov [14], DeKay and McClelland [8], and Brown et al. [1] provide evidence that people are willing to pay (WTP) more to avoid an environmental problem if they think it is man-caused than if they think it is an outcome of nature. Kahneman et al. [13] refer to this as the "outrage effect". Their empirical results suggest that intentional harm caused by humans is considered more upsetting than unintentional harm, and therefore triggers a larger WTP response to ameliorate the problem.

These findings have not settled the debate; rather, they have created another one. Walker et al. [21] dispute the suggestion that people are more upset about man-made disasters than about natural ones, and are hence willing to contribute more to undo them. In a study on how the cause of an environmental problem affects the disparity between WTP and willingness to accept (WTA), they find the opposite result for their WTP values-WTP to undo harm caused by humans was lower than WTP for natural damages. Rather than an "outrage effect" triggered by the distinction between human versus natural causes per se, Walker et al. [21] hypothesize that WTP is driven by the degree of responsibility that people feel for the damages. ${ }^{1}$ Building on this hypothesis, Brown et al. [1] postulate that "the identification of a negligent party that has the ability to pay for some sort of restitution (such as a corporation) will lower the general public's WTP, possibly even below WTP if the loss were caused by a natural process" [1, p. 490].

In this paper, we use responses from a panel of Dutch households to sort out the various arguments. The specific case we consider is conservation of a locally threatened species (seals in the Netherlands). Our first objective is to test whether WTP indeed increases when humans instead of nature (a virus) cause the harm. To disentangle outrage and responsibility effects, we distinguish between two (unintentional) types of human causes: (i) global warming, where society at large is responsible (and arguably everyone, albeit only minimally), and (ii) drilling for oil and gas, where in their pursuit of profits, industry causes the damage. The outrage effect predicts that WTP for both human causes exceeds WTP for the natural cause. The responsibility effect predicts that WTP to undo harm caused by oil- and gas-drilling firms will be lower than WTP to undo harm caused by global warming (and possibly even lower than WTP to undo damages caused by a natural virus).

Our second objective is to investigate the effects of varying the framing of the WTP question in three alternative ways. Cummings and Taylor [6,7], List [15], and Carson et al. [4] find that people make lower bids in hypothetical valuation exercises when reasons for hypothetical bias are explicitly discussed or when they are told that their responses to valuation questions will have real consequences. We test these issues in our field study and elicit WTP with a hypothetical valuation question, with a hypothetical question combined with a form of cheap talk, and finally with a

\footnotetext{
${ }^{1}$ The idea for a moral responsibility effect originates from results in [14] where the human-versus-nature effect is large in case of general pollution but small in case of a human predator. Note, however, that in a similar setting Kahneman et al. [13] find, on the contrary, a large effect in case of a human predator, so that the issue seems far from settled.
} 
hypothetical question indicating that the study results will be considered by policy makers. The factorial experimental design employed allows causes to be crossed with scripts so that both types of treatments can be independently varied.

Several interesting insights are obtained. First, we find evidence supporting the outrage hypothesis. People are WTP significantly more to protect seals when they appear to be threatened by an act of mankind (oil and gas drillers, greenhouse effect), rather than an act of nature (virus). Second, we fail to find evidence in support of the responsibility hypothesis. Third, we find that: (i) stated values obtained using cheap talk and consequential devices are significantly lower than comparable values obtained using a hypothetical question without these treatments, and (ii) stated values across the cheap talk and consequential treatments are statistically indistinguishable. ${ }^{2} \mathrm{~A}$ fourth result potentially sheds light on another ongoing argument in non-market valuation. Cummings et al. [5] compare the outcomes of actual and hypothetical bids and find that hypothetical referenda are not incentive compatible. Haab et al. [11] debate this conclusion, contending that it may be due to heteroskedasticity. Because we vary the bid presented across panellists, we can test for heteroskedasticity using the method developed by Cameron and James [3]. While the script affects bid levels, we do not find support for the hypothesis that the variance is affected when we vary the phrasing of the script. This outcome provides weak support for the position of Cummings et al., but of course does not imply that heteroskedasticity will not be a problem in cases where real payments are considered-exploring this issue is left for future work.

\section{Data and experimental design}

Data were obtained from a survey of participants in the CentERpanel, which consists of more than 2000 households in the Netherlands. Panel members are selected to be representative of the Dutch population. ${ }^{3}$ Panellists receive a "netbox" from CentER, Tilburg University, so that they can retrieve and return questionnaires via a television. To ensure a good response rate, before panellists are selected, they are interviewed to investigate their commitment to completing questionnaires to be sent each week. In practice, when given the chance, a large majority of households agree to be part of the CentERpanel.

The analysis focused on declines in the seal population in the Waddenzee (an estuary in the North of the Netherlands), a problem that has been widely publicized in the Netherlands for many years. The seal population reached a low point of about 300 animals in the 1970s. Currently the number of animals has recovered to some 2000 seals, but that number is still much lower than the 18,000 seals that lived in the Waddenzee in the beginning of last century. The seal population is threatened by three possible and distinct developments. First, new diseases (especially certain viruses) have taken a severe toll on the population in the past and continue to pose a serious threat. ${ }^{4}$ Second, climate change and the associated rise of the sea level might trigger the

\footnotetext{
${ }^{2}$ Of course, it is an open question how these hypothetical payments would compare to the case of real payments. Institutional restrictions on how the panel could be used prevented asking them to make actual cash payments.

${ }^{3}$ Additional information regarding the panel is available at www.centerdata.nl

${ }^{4}$ As a matter of fact, one of these three threats did affect the seal population shortly after completing the data collection. A virus killed a significant share of the population and experts predict that as much as half of the population might die as a result.
} 
disappearance of the seal's breeding grounds. Third, commercial oil and gas drilling may have the same effect, not because the sea level rises, but because the land level falls. The threat from viruses represents the case in which the seal population may be harmed by natural causes for which no societal group is responsible, whereas with oil and gas drilling, actions taken by a comparatively small group of people for private gain contribute directly to the species hardship. Climate change represents an intermediate situation in which virtually everyone is to some extent responsible for the problem.

The survey began with a brief introduction (common to all groups), in which attention was directed to the declining seal population. Then, panellists were presented with a description of one of the three types of threats along with a plausible mitigation measure. These scripts, labelled virus, climate change, and oil and gas drilling, are shown below in translation to English from Dutch.

1. Virus: A number of factors continue to threaten the seal population. One important threat is a new virus that undermines the species' resistance to various diseases. The origins of the virus are unknown, but it is regarded as a "natural enemy" of the seal population. The spreading of the virus is a natural process, independent of human actions. It is possible that, without any preventive actions, the seal population in "the Waddenzee" falls by some $50 \%$. An effective preventive measure would be a vaccination program.

2. Climate change: A number of factors continue to threaten the seal population. One important threat is climate change, mainly caused by burning of fossil fuels. Climate change (or the greenhouse effect) is a global problem because all people using fossil fuels are responsible for the emissions of carbon dioxide in the atmosphere (and not simply people in the Netherlands). An important risk of climate change and the associated rise of the sea level is that breeding grounds will be submerged for longer periods. This will negatively impact on the ability of female seals to deliver and feed young seals. It is possible that, without any preventive actions, the seal population in "the Waddenzee" falls by some $50 \%$. An effective preventive measure would be elevating the existing sand banks by adding sand to them.

3. Oil and gas drilling: A number of factors continue to threaten the seal population. One important threat is drilling for gas by oil and gas companies in "the Waddenzee." An important risk of gas exploitation is that the land level will fall so that breeding grounds will be submerged for longer periods. This will negatively impact on the ability of female seals to deliver and feed young seals. It is possible that, without any preventive actions, the seal population in "the Waddenzee" falls by some $50 \%$. An effective preventive measure would be elevating the existing sand banks by adding sand to them.

After the threat was described, panellists were asked to value conservation measures (vaccinations or elevating sand banks, depending on treatment type) to protect seals from further harm. ${ }^{5}$ In each case, panellists were asked one discrete choice valuation question using one

\footnotetext{
${ }^{5}$ In order to get realistic cases, we have to vary not only the cause but also the solution (proposed intervention) - a vaccination program for the virus threat and elevation of sand banks for the climate change and gas drilling cases. Subramanian and Cropper [20] show that people could also care about the characteristics of regulatory programs, but Kahneman et al. [13] suggest that this effect is relatively unimportant. We ignore the effect of different interventions but, as described more fully below, delete 51 observations where panellists used the debriefing question to object to the proposed solution.
} 
of three scripts. ${ }^{6}$ Scripts used (labelled hypothetical, hypothetical/cheap talk and hypothetical/ consequentialism) are shown below, again in translation to English from Dutch. A WTA script also was included in the survey. Responses to this script are analysed in [2].

1. Hypothetical: The government can decide to take special measures to protect the seal population from the above-mentioned threat. Such measures, however, are costly. Would you be WTP a onetime amount of DFL $X$ to support protection of the seal population? All the money would be used to finance a vaccination program/elevation of sand banks (choose appropriate case). "yes" "no"

2. Hypothetical/cheap talk: The government can decide to take special measures to protect the seal population from the above-mentioned threat. Such measures, however, are costly. Would you be WTP a one-time amount of DFL $X$ to support protection of the seal population? All the money would be used to finance a vaccination program/elevation of sand banks (choose appropriate case).

Note: this is a hypothetical question! You don't have to actually pay the money. In general, people experience difficulties answering hypothetical questions. People typically bid more money then they are really WTP.

One reason why people might be tempted to bid too much is as follows. People try to accept or reject a bid based on their evaluation of the "true value" of the commodity (in this case, seal conservation in "the Waddenzee"). But if people should actually make the payment, they also consider that they can spend their money only once and that money spent on seal conservation is not available for other purchases.

When answering the bid question below, try to think whether you are really WTP this amount for the conservation of seals. Try to imagine that this amount of money is no longer available to finance other purchases.

Would you be WTP a one-time amount of DFL $X$ to protect the seal population? "yes" "no"

3. Consequentialism: The government can decide to take special measures to protect the seal population from the above-mentioned threat. Such measures, however, are costly. Would you be WTP a one-time amount of DFL $X$ to support protection of the seal population? All the money would be used to finance a vaccination program/elevation of sand banks (choose appropriate case).

Note: the results of this study will be made available to policy makers, and could serve as a guide for future decisions with respect to taxation for this purpose. It is important that you think before answering the question.

Would you be willing to pay a one-time amount of DFL $X$ to protect the seal population? "yes"

"no"

\footnotetext{
${ }^{6}$ The dichotomous choice approach was used in the valuation exercise because it appears to be incentive compatible [5], but it has the disadvantage that survey panellists' willingness to pay values are not directly revealed.
} 
The survey concluded with an open-ended de-briefing question that invited panellists to provide comments about any of the questions. About $80 \%$ of panellists did so. Demographic information (income, schooling, age, gender, marital status, family size, province of residence) about panellists was not collected in the survey because it already was available from CentERpanel.

Regarding the elicitation of values, the cheap talk script is a shortened and revised version of the scripts used by Cummings and Taylor [7] and List [15]. While their scripts were longer, orally presented, and describe hypothetical bias in detail, a much shorter version was used here to reduce the amount of material presented to panellists. Our script could be thought of as similar to the shorter cheap talk scripts used by Cummings and Taylor [7] and Poe et al. [17], which failed to eliminate hypothetical bias. Also, use of consequentialism followed as closely as possible Carson et al. [4] and Cummings and Taylor [6], who use randomization devices to provide subjects with uncertainty about whether the exercise will actually be economically binding. ${ }^{7}$ In theory, use of consequentialism should provide panellists with incentives to state their true preferences.

Our $3 \times 3$ experimental design crossed the three causes (virus, climate change, and oil and gas drilling) with the three valuation scripts (hypothetical, hypothetical/cheap talk, and consequentialism). Each panellist was randomly assigned to one of the nine treatment cells. Within each cell, each panellist was presented with a randomly drawn bid from the set (DFL 10, 40, 80, 120, where DFL $2.2 \approx$ Euro $1 \approx$ US $\$ 1$ ). A preliminary version of the questionnaire was administered to 100 panellists who were randomly selected for a pilot test. Among other things, the pilot was used to establish that the questions were understandable and that the bids presented in the experiment roughly spanned the range of values expressed by CentER panellists. The instrument was then revised and in September 2001, it was sent to all panellists who did not participate in the pilot experiment. Panellists had 5 days to complete the survey 'on line,' and no subject was assigned to more than one treatment. In total, 1819 panellists responded - a response rate of more than $95 \%$; and all panellists who responded answered the WTP question presented. Eliminating the 433 panellists that received WTA valuation question reduces the sample to 1386. After reviewing responses to the de-briefing question, the sample was further reduced to 1335 because 51 panellists said either that the threat to seals was not real or that the solution proposed would not work. The relatively low number of objections to the proposed method of intervention is consistent with Kahneman et al. [13], who argue that outcomes are likely insensitive to the types of intervention (also note that both elevation of sand banks and vaccination programs are "plausible" interventions; both have been mentioned in newspapers). Nevertheless, whether these 51 panellists are eliminated from the data set has virtually no effect on the results presented in the next section. ${ }^{8}$

\footnotetext{
${ }^{7}$ To avoid misleading panellists, environmental policymakers in the Netherlands were informed of the study before execution and subsequently briefed on the major results.

${ }^{8}$ Another tabulation of responses to the de-briefing question suggests that some people are opposed to paying for environmental problems caused by oil and gas firms. One conjecture is that these panellists might provide a value because it is the only available way to register their unhappiness with the situation. However, only 33 of 450 panellists who received the oil/gas drilling script stated that they thought firms should pay and that the panellists themselves should not; and of these persons, 31 refused to pay the bid value presented. These 33 responses were retained in the data set. We thank Mark Dickie for encouraging the investigation of this point.
} 


\section{Analysis}

This section analyses whether panellists said they would pay the bid presented to reverse damage to the seal population. Analysis begins by comparing fractions of panellists across treatments that stated they would pay the amount presented in the survey to prevent further harm to the seal population in the Waddenzee. These comparisons, presented in Table 1, should be considered only as suggestive because the percentage of responding panellists that were shown the four bid values differs between treatment cells. As demonstrated momentarily, the likelihood that a panellist would offer to pay the amount presented is smaller for larger bid values. Nevertheless, it is useful to obtain at least a rough idea about treatment effects before proceeding with a more detailed analysis. In pair-wise comparisons of proportions shown in Table 1, panellists in the virus/hypothetical with cheap talk cell are significantly less likely at the $1 \%$ level to agree to pay the stated bid amount than panellists in all other cells. Pair-wise comparisons of proportions setting oil and gas drilling/hypothetical with cheap talk against climate change/consquentialism, virus/consequentialism, and climate change/hypothetical with cheap talk also were significantly different at the $5 \%$ level. $^{9}$

The dichotomous choice responses obtained can be modeled parametrically by specifying the linear WTP function shown in Eq. (1). ${ }^{10}$

$$
\begin{aligned}
Y= & \beta_{0}+\beta_{1} \text { DRILL }+\beta_{2} \text { CLIMATE }+\beta_{3} \text { CHEAPTALK } \\
& +\beta_{4} \text { HYPOTHETICAL }+Z \gamma+u,
\end{aligned}
$$

WTP to protect seals $(Y)$ is expressed in terms of treatment effects (DRILL, CLIMATE, CHEAPTALK, HYPOTHETICAL), a vector of controls for panellist characteristics (Z), and an additive stochastic preference term $(u)$. In Eq. (1), the $\beta_{j}$ and the elements of $\gamma$ are coefficients to be estimated and $u$ is assumed normally distributed with variance $\sigma^{2}$. The constant term, $\beta_{0}$, is interpreted as WTP to avoid the virus threat when values are elicited using consequentialism.

Eq. (1) is estimated using binomial probit because values of WTP are latent. Estimates of $\beta$ and $\gamma$ in Eq. (1) are recovered using methods developed by Cameron and James [3]. Results are shown in Table 2. These estimates are based on 1309 observations, rather than 1335 observations because information about income was missing for 26 panellists. ${ }^{11}$ Standard errors of coefficient estimates were computed via Taylor series expansion. Covariates include treatment cell dummy variables

\footnotetext{
${ }^{9}$ Difference between means tests were performed to test for demographic differences between treatment cells. In the cases of age, whether a partner is present, and gender, the homogeneity null was never rejected at the $5 \%$ level assuming unequal population variances [18]. For gross income, the null hypothesis of no difference between cell means was rejected in one pair-wise comparison, but this outcome occurs because the income of one sample member was an outlier. Mean numbers of household members and mean numbers of children present in the household, however, exhibited more variation between treatment cells and the null hypothesis of no difference between means of these variables was rejected in a few instances. Details of these tests are available through the internet site, http:/ www.aere.org/journal/index/html

${ }^{10}$ A log-linear WTP model also was estimated. Results for both treatment effects and control variables tell essentially the same story as those for the linear WTP model estimates described below.

${ }^{11}$ A regression with 1335 observations specified the same as the one reported in Table 2, but excluding the income variable, yields almost identical results for all other coefficients. There were no missing observations for any of the other variables used in this study.
} 
Table 1

Proportion of "Yes" responses by treatment $(n=1335)$

\begin{tabular}{lccc}
\hline Treatment & Hypothetical & Hypothetical/cheap talk & Consequentialism \\
\hline Virus & 0.526 & 0.356 & 0.501 \\
& $(0.038)$ & $(0.041)$ & $(0.040)$ \\
Climate change & 0.597 & 0.503 & 0.488 \\
& $(0.038)$ & $(0.041)$ & $(0.041)$ \\
Oil and gas drilling & 0.593 & 0.616 & 0.558 \\
& $(0.041)$ & $(0.038)$ & $(0.039)$
\end{tabular}

Standard errors in parentheses.

Table 2

Probit estimates of treatment effects $(n=1309)$

\begin{tabular}{|c|c|c|}
\hline Variable & Mean & Estimates of $\beta$ and $\gamma$ (std. error) \\
\hline Constant & - & $\begin{array}{r}54.30^{\mathrm{a}} \\
(23.45)\end{array}$ \\
\hline Bid value & 62.15 & $-\mathrm{b}$ \\
\hline Oil/gas drilling & 0.339 & $\begin{array}{r}41.88^{\mathrm{a}} \\
(12.84)\end{array}$ \\
\hline Climate change & 0.319 & $\begin{array}{r}28.38^{\mathrm{a}} \\
(12.37)\end{array}$ \\
\hline Virus & 0.342 & $\mathrm{C}^{\mathrm{c}}$ \\
\hline Hypothetical/cheap talk & 0.314 & $\begin{array}{l}-4.26 \\
(12.01)\end{array}$ \\
\hline Hypothetical & 0.347 & $\begin{array}{r}28.92^{\mathrm{a}} \\
(12.23)\end{array}$ \\
\hline Consequentialism & 0.339 & $-^{c}$ \\
\hline Panellist is male & 0.548 & $\begin{array}{r}-36.56^{\mathrm{a}} \\
(10.87)\end{array}$ \\
\hline Household monthly gross income (in Dutch guilders) & 14399.73 & $\begin{array}{c}0.709 \mathrm{E}-04 \\
(.104 \mathrm{E}-03)\end{array}$ \\
\hline Panellist has primary education & 0.045 & $\begin{array}{l}-3.21 \\
(27.14)\end{array}$ \\
\hline Panellist has secondary education & 0.362 & $\begin{array}{c}7.80 \\
(16.31)\end{array}$ \\
\hline Panellist has university education & 0.121 & $\mathrm{C}^{\mathrm{c}}$ \\
\hline Panellist has vocational education & 0.472 & $\begin{array}{c}26.19 \\
(16.04)\end{array}$ \\
\hline Years of age & 46.11 & $\begin{array}{l}-0.08 \\
(0.349)\end{array}$ \\
\hline Proximity to the Waddenzee & 0.082 & $\begin{array}{l}-7.89 \\
(17.81)\end{array}$ \\
\hline
\end{tabular}

${ }^{\mathrm{a}}$ Denotes coefficient significantly different from zero using a $t$-test at the $5 \%$ level or lower.

${ }^{\mathrm{b}}$ The estimate of $\sigma$ is $-(-1 / 0.00733)=136.43$, with standard error of 16.45 .

${ }^{\mathrm{c}}$ Denotes omitted dummy variable. 
and controls for gender, gross household income, schooling, years of age, and whether the panellist lives in Friesland or Groningen (the nearest provinces to the Waddenzee). Other controls, such as panellists' marital status and number of children were included in unreported regressions but coefficients of these variables never differed significantly from zero at the 5\% level. Because treatments were randomly assigned to panellists, they are orthogonal to panellist characteristics. Thus, provided that the true model of WTP is linear as shown in Eq. (1), alternative choices of controls have little effect on the estimated coefficients of the treatment variables.

Six aspects of Table 2 are noted prior to discussing the main results. First, estimates of expected WTP for each panellist, computed by inserting coefficient estimates into Eq. (1) are always positive, ranging from 2.90 DFL to $183.91 \mathrm{DFL}$, with an average of 77.95 DFL across the entire sample. ${ }^{12}$ Second, the null hypothesis that all nine treatments have the same effect on WTP $\left(H_{0}: \beta_{1}=\beta_{2}=\beta_{3}=\beta_{4}=0\right)$ is rejected at the $5 \%$ level using a likelihood ratio test. Third, panellists are significantly less likely at the $5 \%$ level to say they would pay higher bid values than lower bid values. Fourth, women's WTP is larger than WTP among men. Fifth, gross household income, years of age, schooling, and proximity to the Waddenzee are not significant determinants of WTP. ${ }^{13}$ The result for the variable measuring proximity to the Waddenzee suggests that the use value of seals is unimportant. Sixth, the coefficient of the bid value is a point estimate for $-1 / \sigma$, so that an estimate of $\sigma$ across all treatments is $(1.0 / 0.00733)=136.43$. In this context, a question arises whether $\sigma$ varies across different treatments, creating the type of heteroskedasticity problem highlighted by Haab et al. [11] in their comment on Cummings et al. [5]. Additional regressions were run (not presented here), specified in the same manner as Eq. (1), except that the price variable was interacted with the four treatment variables. A likelihood ratio test indicates that the null hypothesis that coefficients of these interaction terms are jointly zero is not rejected at the $5 \%$ level; thus values of $\sigma$ across all treatments are statistically indistinguishable.

Does the source or cause of an environmental problem affect WTP or, in other words, does the outrage effect exist? As typically applied, standard utility theory holds that utility depends solely on outcomes, and that the cause is unimportant. If people value only outcomes and do not care about the cause, then in Eq. (1), $\beta_{1}=\beta_{2}=0$. This joint hypothesis is rejected at the $5 \%$ level using a likelihood ratio test. Also, $t$-tests reject the individual null hypotheses that $\beta_{1}=0$ and $\beta_{2}=0$ at the $5 \%$ significance level. Thus, the oil and gas drilling and the climate change treatments differ from the virus treatment: people are WTP more to avoid man-caused environmental harm than if the harm occurs by an act of nature. These results broadly support the existence of an outrage effect and are consistent with earlier work using museum visitors and undergraduates as subjects $[1,8,13,14] .^{14}$

\footnotetext{
${ }^{12}$ Averages of panellists' expected WTP by cause and by elicitation method are available through the internet site http:/www.aere.org/journal/index/html

${ }^{13}$ Other income measures tried were net income of panellists and gross and net income of the panellist's household. When substituted for gross income of panellists in Table 2 regression, these variables were also insignificant. Dummy variables defined on the quartiles of all four of these variables also were tried with no appreciable change in results. Details are available from the authors upon request.

${ }^{14}$ Now that we find that cause matters, it is of course important to rethink the formal model that underlies the CVM. Smith [19] develops a framework for formulating CVM questions, but we leave possible extensions for future work.
} 
Interestingly, and in contrast to the proposed "moral responsibility effect" advanced by Brown et al. [1] and Walker et al. [21], results in Table 2 do not reject the null hypothesis that $\beta_{1}=\beta_{2}$ at the $5 \%$ level. Thus, WTP is not significantly different at conventional levels when the harm is caused by a specific group of people (oil and gas firms), as compared with when it is caused by society as a whole (climate change from greenhouse gas emissions). In fact, contrary to predictions of the moral responsibility hypothesis, we find that WTP to undo harm caused by corporations does not differ significantly at the 5\% level from WTP to undo harm caused by society. An explanation for our result could be that people are not only driven by moral responsibility, but also consider harm caused to increase a corporation's profits to be more "unfair" than harm caused by society at large, triggering more "outrage" and a larger contribution to offset the damages. Analysing this issue in greater detail is left for another occasion, but see $[9,10]$ for a discussion of "fairness" in economic thinking.

Does the method of eliciting values affect panellists' WTP? If elicitation method does not matter, then in Eq. (1) $\beta_{3}=\beta_{4}=0$. Using a likelihood ratio test, this joint hypothesis is rejected at the $5 \%$ level. Also, in individual $t$-tests at the $5 \%$ level, the null hypothesis that $\beta_{3}=0$ is not rejected and the null hypothesis that $\beta_{4}=0$ is rejected, implying that responses in the hypothetical treatment differ from those in the consequentialism treatment, but there is no such difference between responses in the cheap talk and consequentialism treatments. Further, the null hypothesis of no difference between the hypothetical treatment and the cheap talk treatment $\left(H_{0}: \beta_{3}=\beta_{4}\right)$ is rejected using a likelihood test at the $5 \%$ level. Because heteroskedasticity does not explain these differences, the logical conclusion is that the hypothetical treatment yielded the largest WTP values. Whether these results suggest that value statements in cheap talk and consequentialism treatments map into actual preferences is open for debate; yet, combined with findings from previous studies, these results support the notion that both the cheap talk and consequential treatments can provide plausible value estimates (e.g., $[4,6,7,15]) .^{15}$

The previously discussed probit estimates are obtained under the assumption that the error term, $u$, in Eq. (1) is normally distributed. To examine the possible contribution of this assumption to our results, we considered two alternative tests that do not impose this distributional assumption: (1) $\chi^{2}$ tests for response differences between cause and elicitation scripts and (2) Turnbull lower bound estimates of WTP [12, pp. 72-78]. First, $72 \chi^{2}$ tests for differences in treatment effects (available through the internet site http:/www.aere.org/journal/ index/html) were carried out using the frequencies of yes/no responses to the valuation question in $2 \times 2$ contingency tables for each bid point in the experimental design (see [18]). ${ }^{16}$ Eight tests identified significant differences at the $5 \%$ level that are consistent with the probit results discussed above (differences identified are between the hypothetical and hypothetical/cheap talk scripts, the hypothetical and consequentialism scripts, the oil/gas drilling and virus scripts, the oil/ gas drilling and climate change scripts, and the climate change and virus scripts. Two of the $\chi^{2}$ tests show a significant difference between the hypothetical/cheap talk and consequentialism

\footnotetext{
${ }^{15}$ See List and Shogren [16] for a literature review of the comparison between hypothetical and actual statements of value.

${ }^{16}$ Thirty-six $(4 \times 3 \times 3) \chi^{2}$ tests compared responses to two elicitation scripts for given causes and bid values, and 36 additional tests compared responses to two causes for given elicitation scripts and bid values. Results of these tests are available through the internet site $h t$ tp:/www.aere.org/journal/index/html
} 
scripts. However, in one case, the fraction of "yes" answers to the hypothetical/cheap talk script exceeded that for the consequentiaism script, whereas in the other case the reverse outcome obtained. This outcome may be responsible for the result reported in Table 2 indicating no significant difference between these two treatments. Overall, the comparatively small number of significant differences found in the $\chi^{2}$ tests suggests that differences between treatment effects may not be large and the probit analysis may be allowing a few design points to dominate the results.

Second, the Turnbull estimates (available through the internet site http:/www.aere.org/journal/ index/html) were compared with the probit estimates described above. Unlike the probit estimates, the Turnbull estimates of WTP are confined to the positive domain, assume that everyone in a given treatment cell has the same WTP, and make no use of covariates. Thus, the Turnbull estimates are computed using all of the available 1335 observations. Standard difference between means tests show that the Turnbull WTP estimates are: (1) significantly larger at the 5\% level for treatments using the hypothetical question than for those using either cheap talk or consequentialism and (2) larger for treatment cells involving oil and gas drilling, although the differences are not always statistically significant at the 5\% level. Also, for two treatment cells (oil and gas drilling/hypothetical with cheap talk, oil and gas drilling/hypothetical) the Turnbull WTP estimates were smaller than the smallest value of WTP predicted for those cells by the probit model. In three (two) treatment cells, the Turnbull WTP estimates were in the lower (upper) half of the range of values of WTP predicted for those cells by the probit model. Turnbull estimates of WTP could not be computed for two treatment cells (oil and gas drilling/consequentialism, virus/ hypothetical) because the percentage of "no" responses did not increase monotonically with the bid values.

\section{Conclusions}

We conducted a field experiment using a large Dutch panel to examine the effects of context and framing on the WTP to conserve seals in the Netherlands. Based on our probit analysis, we cautiously draw several conclusions. We find that WTP to protect seals from harm is affected by the nature of the threat. The patterns of results suggest that the "outrage effect" plays a role. We also find that framing matters - stated WTP is conditional on whether bid values are elicited with hypothetical questions, or using a hypothetical format that either contains "cheap talk" or mention of possible consequences of the survey. We find that stated values in "cheap talk" and "consequentialism" treatments are significantly lower than stated values in a hypothetical question without these additions. We also find that alternative tests that do not impose the normality assumption do not discriminate between these effects as sharply as those based on the probit analysis.

Consistent with earlier psychological work, we find evidence to support the hypothesis that preferences are conditional on attributes of choice. From a normative perspective, if these attributes are important, then a good deal of economic theory should be reconsidered as utility is typically measured over outcomes, not over what induced that outcome and the context in which it occurred. In a positive sense, if antecedents are important, then policymakers must take into account this information when crafting policy. 
On the brighter side, the finding concerning the method of eliciting WTP is encouraging. Since it is difficult to move beyond hypothetical surveys, it is of considerable interest to understand whether panellists take the valuation question seriously. Interestingly, the cheap talk and consequentialism treatments yield comparable value estimates. This suggests that CVM studies can be improved by including these devices.

One might speculate that providing additional information about the consequences of the stated bid (in terms of foregone consumption opportunities or impact on policy-making) triggers a move from one mental map to another-almost as if a switch is flipped. When responding to purely hypothetical questions, people may not provide their full attention. Yet when reminded of the consequences of their actions, a 'serious' response is warranted. Our results indicate that exactly how people are reminded does not seem to matter much. We suspect this will be a topic of considerable future interest given that CVM remains the "only game in town" to gather total values of non-marketed goods and services.

\section{References}

[1] T.C. Brown, D. Nannini, R.B. Gorter, P.A. Bell, G.L. Peterson, Judged seriousness of environmental losses: reliability and cause of loss, Ecolog. Econ. 42 (2002) 479-491.

[2] E. Bulte, S. Gerking, J.A. List, A. de Zeeuw, Do causes of environmental problems affect Hicksian equivalent surplus? Evidence from the field, Econ. Lett., forthcoming.

[3] T.A. Cameron, M.D. James, Efficient estimation methods for "closed-ended" contingent valuation surveys, Rev. Econ. Statist. 69 (1987) 269-276.

[4] R.T. Carson, T. Groves, J.A. List, M. Machina, Probabilistic influence and supplemental benefits: a field test of the two key assumptions underlying stated preferences, Working Paper, University of California, San Diego, 2002.

[5] R.D. Cummings, S. Elliott, G. Harrison, J. Murphy, Are hypothetical referenda incentive compatible?, J. Polit. Economy 105 (1997) 609-621.

[6] R.D. Cummings, L. Taylor, Does realism matter in contingent valuation surveys?, Land Econ. 74 (1998) 203-215.

[7] R.D. Cummings, L. Taylor, Unbiased value estimates for environmental goods: a cheap talk design for the contingent valuation method, Amer. Econ. Rev. 89 (1999) 649-665.

[8] M.L. DeKay, G.H. McClelland, Probability and utility components of endangered species preservation programs, J. Exp. Psychol.: Appl. 2 (1996) 60-83.

[9] E. Fehr, K.M. Schmidt, A theory of fairness, competition and cooperation, Quart. J. Econ. 114 (1999) 817-868.

[10] E. Fehr, S. Gachter, Cooperation and punishment in public good experiments, Amer. Econ. Rev. 90 (2000) 980-994.

[11] T.C. Haab, J.C. Huang, J.C. Whitehead, Are hypothetical referenda incentive compatible? a comment, J. Polit. Economy 107 (1999) 186-196.

[12] T.C. Haab, K.E. McConnell, Valuing Environmental and Natural Resources, The Econometrics of Non-market Valuation, Edward Elgar, Cheltenham, 2002.

[13] D. Kahneman, I. Ritov, K.E. Jacowitz, P. Grant, Stated willingness to pay for public goods: a psychological perspective, Psychol. Sci. 4 (1993) 310-315.

[14] D. Kahneman, I. Ritov, Determinants of stated willingness to pay for public goods: a study in the headline method, J. Risk Uncertainty 9 (1994) 5-38.

[15] J.A. List, Do explicit warnings eliminate the hypothetical bias in elicitation procedures?: Evidence from field auctions for sportscards, Amer. Econ. Rev. 91 (2001) 1498-1507.

[16] J.A. List, J. Shogren, Calibration of willingness-to-accept, J. Environ. Econ. Manage. 43 (2002) 219-233.

[17] G. Poe, J. Clark, W. Schulze, Can hypothetical questions predict actual participation in public programs? A field validity test using a provision point mechanism, Working Paper, Cornell University, 1999. 
[18] D.J. Sheskin, Handbook of Parametric and Nonparametric Statistical Procedures, CRC Press, New York, 2000.

[19] V.K. Smith, Pricing what is priceless: a status report on non-market valuation of environmental resources, in: H. Folmer, T. Tietenberg (Eds.), The International Yearbook of Environmental and Resource Economics 1997/1998, Edward Elgar, Cheltenham, 1997, pp. 156-204.

[20] U. Subramanian, M. Cropper, Public choices between life saving programs: the tradeoff between qualitative factors and life saved, J. Risk Uncertainty 21 (2000) 117-149.

[21] M.E. Walker, O.F. Morera, J. Vining, B. Orland, Disparate WTA-WTP disparities: the influence of human versus natural causes, J. Behavioral Dec. Making 12 (1999) 219-232. 